\title{
Clinical effects of solifenacin succinate combined with other drugs in treating overactive bladder after transurethral resection of the prostate.
}

\author{
Jiasheng Hu ${ }^{1}$, Dongxu Zhang ${ }^{1}$, Jun Guan ${ }^{2 *}$ \\ ${ }^{1}$ Department of Urology Surgery, the First Hospital of Ningbo, Ningbo Zhejiang Province, PR China \\ ${ }^{2}$ People's Hospital of Huishan District, Wuxi Jiangsu, PR China
}

\begin{abstract}
Purpose: This research was aimed to explore the clinical situations of solifenacin succinate combined with tamsulosin in treating OAB after TURP.

Methods: During experiment, the diagnosed subjects were randomly included into the treatment group and control group, the treatment lasted 7 10 d, $5 \mathrm{mg}$ of solifenacin succinate and $0.2 \mathrm{mg}$ of tamsulosin were given by oral administration once every one day. Scores were assessed as per relevant reference standards (OABSS, IPSS and QOP) before and after treatment.

Results: In treatment group, compared with before treatment group, OABSS, IPSS and QOP after treatment decreased significantly after treatment $(p<0.05)$. In control group, compared with before control group, OABSS, IPSS and QOP after treatment decreased significantly after treatment $(p<0.05)$. Conclusion: It can be seen that the solifenacin succinate combined with other drugs has obvious curative effects and less side effects, which can benefit patients in the quality of life and disease treatment.
\end{abstract}

Keywords: Solifenacin succinate, Overactive bladder, Transurethral resection.

Accepted on October 31, 2017

\section{Introduction}

In the senile male diseases of urinary system, the Benign Prostatic Hyperplasia (BPH) is more common [1], and the open prostatectomy is used to treat such disease previously. Currently, the Transurethral Resection of the Prostate (TURP) has become the mostly performed and most effective treatment method. It has the advantages as follows: minimal invasion, less recovery time and less postoperative complications compared to the open prostatectomy, but the Postoperative Overactive Bladder (OAB) often troubles the patients [2], and symptoms like infection, bleeding, incision pain, urinary urgency, frequent micturition and urinary incontinence often exist. Due to preoperative unstable bladder, operation irritation, prostatic tissues not completely sucked and urine irritation on the unhealed wound, after the catheter is pulled out after operation, the patient's bladder will still have some pathologic reactions such as involuntary frequent contractions, which is the OAB. $M$ receptor antagonists have been widely used in treating patients with $\mathrm{OAB}$ in clinic, for the various drugs, the solifenacin succinate is highly selective for M3 receptor and is a family member for muscarinic receptor M3 antagonist, by which, the smooth muscle spasm can be relieved. So, it is a drug of first choice for treating OAB. Clinically, the effective combination of choline receptor combined antagonist (solifenacin succinate) and $\alpha$ receptor antagonist (tamsulosin) has better curative effects [3]. To explore the clinical situations of solifenacin succinate combined with tamsulosin in treating
OAB after TURP, 43 cases with OAB after accepting TURP from the year of 2014 to 2015 were selected for treatment and observation. The relevant situations were as follows.

\section{Data and Methods}

\section{General data}

84 patients who met the treatment standards were selected from patients accepting urology treatment from the year of 2014 to 2015, with ages 53 67 and average age $56.4 \pm 3.2$, there existed no statistical differences in ages, heights and weights between control group and experiment group, before operation, a series of examinations were performed for diagnosis and selection, then the patients were included.

\section{Diagnosis standards}

The subjects were diagnosed as per The Guidelines for diagnosis and treatment of diseases in the Department of Urology (version 2007). Inclusive criteria: patients who accepted BPH operation and suffered from clonic spasm pain accompanied by (or not accompanied by) the urge incontinence for four times during indwelling catheter period within one week after operation. Exclusive criteria: the patients whose catheters were blocked by prostate pieces or blood clots; those who were allergic to solifenacin succinate and incompatible to the anticholinergic drugs; those with serious injury of hepatic 
and renal functions and with apparent urinary tract infection and bladder calculi and other symptoms.

\section{Study methods}

Administration: During experiment, the diagnosed subjects were randomly included into the treatment group and control group, the treatment lasted $7 \sim 10 \mathrm{~d}, 5 \mathrm{mg}$ of solifenacin succinate and $0.2 \mathrm{mg}$ of tamsulosin were given by oral administration once every one day. Scores were assessed as per relevant reference standards (OABSS, IPSS and QOP) before and after treatment [4], and the recorded and analysed results were compared. The adverse effects and incidence of drugs were recorded during treatment period.

Indexes: The postoperative bladder spasm attack frequency and duration, urination frequency per day, urinary volume and urge incontinence frequency were recorded, the curative effects were classified into excellent, effective and non-effective.

\section{Statistical methods}

The experimental results were expressed in mean \pm standard deviation, t-test and SPSS 15.0 statistical software were used for analysis, $\mathrm{P}<0.05$ was considered statistically significant difference.

\section{Results}

The subjects hospitalized in our hospital for treatment were observed and treatment situations were recorded, for the treatment group, the drugs were given for $7 \sim 10 \mathrm{~d}$, then suspended after the symptoms of urinary incontinence and frequent micturition were relieved and even disappeared. During study, we assessed the OABSS, IPSS and QOP of the two groups before and after the treatment. After receiving treatment with combined drugs, there were statistical differences in three scores for treatment group and control group, while before receiving the treatment, there was no statistical difference, as shown in Table 1. During treatment, 2 subjects had dry mouth symptom, and without other adverse reactions such as headache and constipation. The relevant treatment indexes like bladder spasm attack frequency and duration improved for two groups, showing no statistical significance; the urination frequency per day, urinary volume and urge incontinence frequency were recorded, analysed and compared, indicating statistical differences between the two groups. During treatment, only one patient in the treatment group had thirst symptom, one patient had nausea and vomiting for one time, the rest patients had no apparently adverse reactions, as shown in Tables 2 and 3.

Table 1. OABSS, IPSS and QOP of the two groups before and after the treatment. Note: ${ }^{*} P<0.05$, compared to the treatment group, t test was used.

Treatment group

Control group

\begin{tabular}{lllll}
\cline { 2 - 5 } & $\begin{array}{l}\text { Before } \\
\text { treatment }\end{array}$ & $\begin{array}{l}\text { After } \\
\text { treatment }\end{array}$ & $\begin{array}{l}\text { Before } \\
\text { treatment }\end{array}$ & $\begin{array}{l}\text { After } \\
\text { treatment }\end{array}$ \\
\hline OABSS score & $10.32 \pm 2.31$ & $2.68 \pm 1.14^{*}$ & $11.02 \pm 2.84$ & $10.43 \pm 2.65^{*}$ \\
\hline QOL score & $16.23 \pm 7.12$ & $11.02 \pm 2.64^{*}$ & $17.65 \pm 7.12$ & $15.43 \pm 9.21^{*}$ \\
\hline IPSS score & $4.67 \pm 1.73$ & $2.09 \pm 1.53^{*}$ & $4.68 \pm 1.76$ & $4.73 \pm 1.02^{*}$ \\
\hline
\end{tabular}

Table 2. Bladder spasm attack frequency and duration. Note: ${ }^{*} P<0.05$ showed statistical difference between treatment group and control group.

\begin{tabular}{llll}
\hline Groups & Number $(\mathbf{n})$ & Spasm frequency & Duration/min \\
\hline Control group & 43 & $7.12 \pm 1.98$ & $10.76 \pm 2.13$ \\
\hline Treatment group & 41 & $4.65 \pm 1.02^{*}$ & $7.62 \pm 1.04^{*}$
\end{tabular}

Table 3. The urination frequency per day, urinary volume and urge incontinence frequency. Note: ${ }^{*} P<0.05$ showed statistical difference between treatment group and control group.

\begin{tabular}{|c|c|c|c|}
\hline Groups & $\begin{array}{l}\text { Urination } \\
\text { frequency } \\
\text { day }\end{array}$ & $\begin{array}{l}\text { Urinary } \\
\text { volume/ml }\end{array}$ & $\begin{array}{l}\text { Urge } \\
\text { incontinence } \\
\text { frequency/time }\end{array}$ \\
\hline Control group & $8.32 \pm 0.38$ & $651.32 \pm 7.43$ & $3.78 \pm 0.26$ \\
\hline Treatment group & $4.65 \pm 0.31^{*}$ & $1263.31 \pm 10.21^{*}$ & $0.51 \pm 0.17^{*}$ \\
\hline
\end{tabular}

\section{Discussion}

During TURP, the normal catheter must be indwelled, but $\mathrm{OAB}$ symptoms such as frequent micturition, urgent micturition or urge incontinence could occur, under physiological status, the excessive activity of detrusor could result in these adverse symptoms [5]. During the bladder urine storage, OAB could occur. During urine storage, the bladder detrusor could involuntarily contract, the pressure in bladder would suddenly rise, generally, the person had to discharge urine immediately, in case the urine failed to be discharged, the urinary incontinence would occur. As to the pathogenesis, the abnormal contraction of bladder detrusor could result in OAB, thus, the stability during bladder filling period was most important.

The bladder and prostatic smooth muscle were important in human urinary system, under normal physiological status, the cholinergic receptor and adrenal gland could effectively control their contraction and relaxation, $M$ choline receptor and $\alpha 1$ receptor could act on prostate and bladder detrusor to result in normal extraction [6,7], and act on the trigone of urinary bladder and urethral sphincter to result in relaxation $[8,9]$. In clinic, the anticholinergic agents were universally and widely applied, in human's some tissues and organs like salivary gland and gastric and intestinal smooth muscle, M3 receptors were widely distributed. Usage could result in thirst, uncontrolled urination, urination constipation and other adverse reactions, so, single use of such drugs could increase incidence of urinary retention. Currently, obstruction relief drugs were given or operation was performed to improve symptoms, two researches TSUJIMURA [10] and KAPLAN [11] showed that the 
combined use of $\alpha 1$-adrenergic receptor blockers and $\mathrm{M}$ receptor blocker was more reliable in clinical safety and could reduce the incidence of urinary retention [12-14], while single use of $\alpha 1$-adrenergic receptor blockers had better curative effects and less adverse reactions than combined use in treating $\mathrm{OAB}$, so, anticholinergic agents or combined use of other drugs were the first choice in clinic. TURP was common in treating $\mathrm{OAB}$ in clinic. Some related irritation factors resulted in damage of bladder detrusor function, contraction existed but inhibition disappeared. Meanwhile, the blood clots and endogenous substances would result in obstruction obstacle at bladder exit, and detrusor malfunction existed in partial patients. So, obstruction relief operation would possibly result in $\mathrm{OAB}$, bleeding and pain, such postoperative damages would bring extreme inconveniences to life of patients, so, treatment of OAB after TURP was of very importance and significance.

When studying the solifenacin succinate combined with other drugs for treating $\mathrm{OAB}$, the comparative results after OABSS scores, QOL scores and IPSS scores were assessed before and after operation showed that OAB patients accepting TURP improved relatively, like improvement of life quality, relaxation of psychological state and less adverse reactions. During treatment, only one patient in the treatment group had thirst symptom, one patient had nausea and vomiting for one time, the rest patients had no apparently adverse reactions. Subsequently, certain dosage of solifenacin succinate combined with tamsulosin was given to treatment group, and placebo was given to control group, the treatment lasted for $5 \sim 10$ d. During treatment, the patients' bladder spasm frequency, duration and other treatment indexes were recorded and compared, showing improved than those before treatment; the urination frequency per day, urinary volume and urge incontinence frequency were recorded and compared, indicating improved than those before treatment.

It can be seen that the solifenacin succinate combined with other drugs has obvious curative effects and less side effects, which can benefit patients in the quality of life and disease treatment. Such method shall be widely utilized and promoted in treating this kind of disease, to lower pain and pressure of patients and greatly reduce the medical risks of medical staff. It can reduce the patients' bladder spasm attack frequency and shorten duration, so, the pain of patients will gradually disappear. This study can provide clinical references and theoretical basis for OAB patients after TURP and medical staff for treating such patients.

\section{References}

1. Price DA, Ramsden PD, Stobbart D. The unstable bladder and prostatectomy. Br J Urol 1980; 52: 529-531.

2. Malhotra B, Gandelman K, Sachse R, Wood N, Michel MC. The design and development of fesoterodine as a prodrug of 5-hydroxymethyl tolterodine (5-HMT), the active metabolite of tolterodine. Curr Med Chem 2009; 16: 4481-4489.
3. Wang Y, Shao J, Lv Y. Efficacy of solifenacin and tamsulosin for treatment of men with lower urinary tract symptoms and overactive bladder. Clinic Med Eng 2010; 17: 38-40.

4. Homma Y, Yoshida M, Seki N Symptom assessment tool for overactive bladder syndrome-overactive bladder symptom score. Urology 2006; 68: 318-323.

5. Yin F, Chen H, Luo X. Clinical study of solifenacin in treating patients with overactive bladder after transurethral resection of prostate. J Mod Urol 2012; 17: 571-574.

6. Johtake A, Saitoh C, Yuyama H. Plarmacological characterization of a new antimuscarinic agent, solifenacin succinate, in comparison with other antimuscarinic agents. Z Pharm Bull 2007; 30: 54.

7. Suzuki M, Ukai M, Ohtake A. Pharmaceutical composition for treating overactive bladder. EP US8772315 2014.

8. Ohtake A, Saitoh C, Yuyama H, Ukai M, Okutsu H. Pharmacological characterization of a new antimuscarinic agent, solifenacin succinate, in comparison with other antimuscarinic agents. Biol Pharm Bull 2007; 30: 54-58.

9. Cetinel B, Onal B. Rationale for the use of anticholinergic agents in overactive bladder with regard to central nervous system and cardiovascular system side effects. Korean J Urol 2013; 54: 806-815.

10. Tsujimuraa T, Uchida C. Clinical efficacy of tolterodine for patients with overactive bladder after in sufficient efficacy by monotherapy with alphal-adrenoceptorantagomist. Nippon Hinyokika Gakkai Zasshi 2009; 100: 686-692.

11. Kaplan SA, Roehrborn CG, Chancer M. Extended-release tolterodine with or without tamsulosin in men with lower urinary tract symptoms and overactive bladder: effects on urinary symptoms assessed by the International Prostate Symptom Score. BJU Int 2008; 102: 1133-1139.

12. Herschorn S, Stothers L, Carlson K. Tolerability of $5 \mathrm{mg}$ Solifenacin once daily versus $5 \mathrm{mg}$ oxybutynin immediate release 3 times daily: Results of the vector trial. J Urol 2010; 183: 1892-1898.

13. Cipullo LM, Zullo F, Cosimato C. Pharmacological treatment of urinary incontinence. Fem Pelvic Med Reconstr Surg 2014; 20: 185.

14. Gormley EA, Lightner DJ, Faraday M, Vasavada SP, American Urological Association; Society of Urodynamics, Female Pelvic Medicine. Diagnosis and treatment of overactive bladder (non-neurogenic) in adults: AUA/SUFU guideline amendment. J Urol 2015; 193: 1572-1580.

\section{*Correspondence to}

Jun Guan

People's Hospital of Huishan District

PR China 